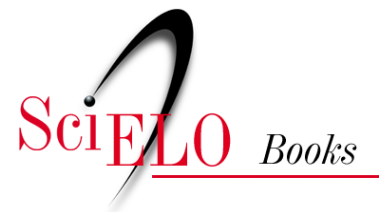

EDUFU

\title{
A escrita na universidade uma reflexão a partir do que os alunos dizem em seus textos
}

\author{
Luciene Juliano Simões \\ Maristela Juchum
}

\section{SciELO Books / SciELO Livros / SciELO Libros}

SIMÕES, L.J., and JUCHUM, M. A escrita na universidade: uma reflexão a partir do que os alunos dizem em seus textos. In: AGUSTINI, C., and ERNESTO, B., eds. Incursões na escrita acadêmicouniversitária: letramento, discurso, enunciação [online]. Uberlândia: EDUFU, 2017, pp. 93-106. ISBN: 978-65-86084-26-9. https://doi.org/10.7476/9786586084269.0006.

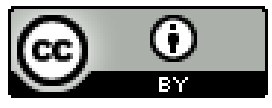

All the contents of this work, except where otherwise noted, is licensed under a Creative Commons Attribution 4.0 International license.

Todo o conteúdo deste trabalho, exceto quando houver ressalva, é publicado sob a licença Creative Commons Atribição 4.0. 


\section{A escrita na universidade: uma reflexão a partir do que os alunos dizem em seus textos}

Luciene Juliano Simões

Maristela Juchum

Nos últimos anos, no Brasil, alguns pesquisadores (Fischer, 2007, Motta-Roth e Hendges, 2010, Marinho, 2010, Fiad, 2011) vêm demonstrando uma maior preocupação em relação à leitura e à escrita dos alunos que ingressam na universidade. As recentes pesquisas apontam que os estudantes calouros apresentam sérias dificuldades em produzir gêneros tipicamente da esfera acadêmica (na modalidade escrita podemos citar o resumo, a resenha, o relatório, entre outros); essas dificuldades são bastante acentuadas quando se trata de alunos atendidos pelas instituições privadas - geralmente, oriundos de camadas sociais menos favorecidas e que há até pouco tempo não tinham acesso ao ensino de nível superior. Diante de um novo perfil de aluno, precisamos produzir novos conhecimentos e novos projetos curriculares para atender às necessidades desses estudantes.

Nesse contexto, temos assistido à criação de disciplinas com o propósito de preparar os estudantes para dominar os textos e as práticas necessárias ao seu sucesso acadêmico (cf. Lea; Street, 1998; 2006; Street, 2009). É o caso da disciplina de Leitura e Produção de Texto I que passou a integrar o currículo das universidades. Subjacente a tal medida, encontrase a "queixa frequente entre professores universitários de que os alunos que entram na universidade estão mal preparados para o ensino a que vão ser expostos", alegando que os saberes e competências de leitura e escrita 
desses alunos não estão adequados às várias comunidades discursivas que integram a universidade (Henderson; Hirst, 2006, p.25). Segundo essas autoras, "o letramento acadêmico é construído no interior de discursos do déficit e remediação" (Henderson; Hirst, p.26).

Segundo Marinho (2010), essa dificuldade ou lacuna de saber costuma ser simplificada por outra crença subjacente aos discursos correntes segundo a qual basta aprender (e principalmente treinar) um conjunto de estratégias textuais, de conteúdos gramaticais, de regras e convenções típicas do texto acadêmico, para que essas dificuldades sejam resolvidas.

Não diminuindo a importância das habilidades e competências linguísticas relacionadas à textualidade, aos aspectos e dispositivos formais e da linguagem acadêmica, argumento que nesse nível não estariam as maiores dificuldades dos nossos estudantes e nem seria muito difícil arregimentar estratégias para melhoria das habilidades desses estudantes. $O$ mais importante seria então convidar esses alunos a interrogar as práticas acadêmicas de letramento das quais eles participam, buscando compreender como se constituem essas práticas $s_{\alpha}$ desenhando um quadro mais complexo de questões relacionadas, sim, a habilidades linguísticas, mas sobretudo a dispositivos que refletem relações de poder, disputas e violência simbólica (Marinho, 2010, p.6, grifos nossos).

Nessa mesma perspectiva, Russel (2009, p.247) afirma que a educação em massa traz consigo uma visão pré-moderna de escrita como conjunto único e generalizável de habilidades que se aprende uma vez e para sempre. Considera-se que os alunos cuja escrita não está em conformidade com os padrões da academia em específico apresentam algum déficit que precisa ser remediado antes que eles sejam admitidos na universidade.

Contrariando essa ideia, Fischer (2010) alega que é nos eventos de letramento acadêmico que os alunos vão construindo os seus saberes acadêmicos/científicos e, para além disso, também os posicionamentos ideológicos, significados culturais e estruturas de poder que, em conjunto, constituem o modo cultural de usar os textos.

Bakhtin (1997, p.303) tece um forte e conhecido argumento para se repensar certa maneira com que se lida com as dificuldades de leitura e de escrita dos alunos na universidade: o domínio de um gênero é uma forma de ação social. Isso significa que é possível ter um bom domínio da língua, 
mas ser inexperiente na atividade de moldar os gêneros. A experiência é algo constitutivo da prática nas comunidades que fazem uso de determinados gêneros, tornando-se, assim, condição indispensável para uma interação verbal bem-sucedida. Assim, torna-se mais coerente esperar e aceitar que os alunos universitários se familiarizem e aprendam a ler e a escrever os gêneros acadêmicos, sobretudo, na instituição e nas esferas do conhecimento em que são constituídos, quando se inserem nas práticas de escrita universitária. E onde, pois, os estudantes poderiam se inserir nas práticas de leitura e escrita de gêneros acadêmicos, se não nas próprias universidades?

\section{A escrita na universidade}

Este trabalho situa-se na discussão sobre escrita na universidade esboçada acima e tem como objetivo principal observar, com base em discussões recentes sobre o letramento acadêmico, feitas por estudiosos dos Estudos sobre o Letramento, o que alunos universitários dizem sobre suas escritas, mais especificamente, como eles veem suas escritas em confronto com o que é esperado no contexto acadêmico.

Segundo Fiad (2011), uma pergunta que fazia parte das discussões sobre a escrita na universidade nos anos 80 era a seguinte: Por que os estudantes chegam à universidade "sem saber escrever"? Para a autora, se a pergunta podia ser essa naquele tempo, hoje não pode mais ser a mesma. "Não é mais possível dizer que os estudantes não sabem escrever, de modo genérico e absoluto" (Fiad, 2011, p.360).

Se, naquela época, era possível ver o desempenho na escrita como habilidades individuais de ler e escrever, adquiridas principalmente na escola básica, hoje é necessário situar qualquer prática envolvendo leitura e a escrita em um contexto sócio-histórico-cultural específico.

São muitas as pessoas que, dominando magnificamente a língua, sentem-se logo desamparadas em certas esferas da comunicação verbal, precisamente pelo fato de não dominarem, na prática, as formas do gênero de uma dada esfera. Não é raro o homem que domina perfeitamente a fala numa esfera da comunicação cultural saber fazer uma explanação, travar uma discussão científica, intervir a respeito de problemas sociais, calar-se ou então intervir de uma maneira muito desajeitada numa conversa social (Bakhtin, 1997, p.303). 
Levando essas reflexões ao ensino superior, segundo Fischer (2007), muitas questões diferenciam o meio acadêmico de outros contextos de ensino. As práticas de leitura e escrita encontradas no ensino superior diferem das práticas anteriores à entrada na universidade.

Neste trabalho, toma-se o conceito de letramento como a relação de uso que um indivíduo ou uma comunidade estabelece com a escrita, rejeita-se o discurso da crise. Ao contrário do que dizem muitos professores universitários em relação à escrita de seus alunos, entende-se que esses estudantes são letrados e, muito provavelmente, não se inseriram ainda nas práticas letradas esperadas no contexto acadêmico.

Analisar e entender o que os alunos escrevem sobre suas escritas é um modo de penetrar nessas práticas de escrita que estão em conflito com as práticas do letramento acadêmico, no momento de entrada na universidade. Assim, analiso textos produzidos por alunos de diferentes cursos, matriculados na disciplina de Leitura e Produção de Texto I, de um Centro Universitário situado no Vale do Taquari/RS. Essa disciplina é obrigatória para todos os alunos da instituição, tem o intuito de lhes ensinar a escrita acadêmica, que é esperada nas diferentes disciplinas do currículo de cada curso.

Como docente dessa disciplina, na primeira aula, proponho aos estudantes a escrita de um texto no qual relatem experiências relacionadas ao seu processo de leitura e escrita desde a entrada na escola de ensino fundamental. Dentre os textos produzidos pelos alunos no início do semestre A de 2013, selecionei os textos de uma turma composta por 45 alunos. Para a realização deste estudo, tomo como referência o texto produzido por cada um dos alunos que integraram a turma, totalizando 45 textos ${ }^{1}$.

Com base nas reflexões sobre letramento acadêmico trazido no interior dos Novos Estudos do Letramento, analiso os textos, buscando fazer uma aproximação entre as reflexões feitas pelos alunos e as reflexões desses autores, que têm discutido o ensino da escrita no contexto acadêmico considerando os alunos como sujeitos letrados e iniciantes em práticas letradas até então desconhecidas. Primeiramente apresento alguns pressupostos dos Novos Estudos do Letramento, nos quais está baseada a discussão feita, após discuto os textos dos alunos.

\footnotetext{
${ }^{1}$ Os textos que compõem o corpus do trabalho integram o acervo de pesquisa aprovada pelo COEP, Comitê de Ética e Pesquisa do Centro Universitário em que a pesquisa foi desenvolvida. Os participantes assinaram o Termo de Consentimento dos materiais para fins de pesquisa.
} 


\section{Os novos estudos do letramento}

Os estudiosos do letramento que integram a área dos Novos Estudos do Letramento (Street 1994, 2003; Barton 2007; Gee 2004) propõem que as práticas de letramento, como práticas sociais que são, têm caráter situado, ou seja, têm significados específicos em diferentes instituições e grupos sociais. Desse modo, assumindo que as práticas de uso da escrita são diferentes, ou seja, que os usos diferem de acordo com o contexto em que são empregados, é possível falar em letramento acadêmico. Mais ainda: assume-se que há usos específicos da escrita no contexto da universidade, usos que diferem de outros contextos.

Boa parte das pesquisas sobre letramento acadêmico surge a partir da observação das escritas de estudantes oriundos de diferentes classes sociais e etnias. Ao entrarem na universidade, os estudantes são requisitados a escreverem diferentes gêneros, com os quais não estão familiarizados em suas práticas de escrita em outros contextos e são mal avaliados por seus professores. Na verdade, como apontam autores como Lea e Street (1999), começam a ficar evidentes os conflitos entre o que os professores esperam das escritas e o que os alunos escrevem; ou seja, no contexto da universidade, em que geralmente não são reconhecidos diferentes letramentos (nesse caso, os dos alunos e o da universidade), os letramentos dos alunos não são reconhecidos e estes são vistos como sujeitos iletrados pela universidade.

A noção de letramento acadêmico, desenvolvida dentro da área dos Novos Estudos do Letramento (Street, 1984; Barton, 2007; Gee, 2004), constitui-se em uma tentativa de extrair as implicações dessa abordagem para o entendimento das questões relativas à aprendizagem no ensino superior. Lea e Street (1998) apontam que a escrita do estudante universitário é compreendida a partir de três principais perspectivas ou modelos: estudo das habilidades, socialização acadêmica e letramento acadêmico.

A primeira abordagem compreende o letramento como um conjunto de habilidades individuais e cognitivas que os estudantes precisam adquirir e desenvolver e que poderão transferir para os diversos contextos da universidade. Ver o letramento apenas dentro desse modelo é desconsiderar a trajetória anterior de letramento do aluno e atribuir a ele a responsabilidade de desenvolver competências cognitivas e metacognitivas de leitura e escrita para inserir-se no contexto da universidade, de manei- 
ra que qualquer insucesso com o uso da escrita, nesse domínio, passa a ser de inteira responsabilidade do aluno.

É necessário destacar que não estou dizendo que o aluno não deva desenvolver habilidades de leitura e escrita específicas da esfera acadêmica, mas, para que isso aconteça, é preciso considerar suas experiências de leitura e escrita antes de ingressar na universidade, com o objetivo de conhecer o que o aluno lê, como lê, o que escreve e como escreve ao ingressar na universidade.

O modelo da socialização acadêmica parte do princípio de que o professor é responsável por introduzir os alunos na cultura universitária, com o intuito de que eles assimilem os modos de falar, pensar, interpretar e usar as práticas de escrita que circulam na esfera acadêmica. Esse modelo parte da concepção de que os gêneros discursivos acadêmicos são relativamente homogêneos e, sendo assim, uma vez que o aluno aprende as convenções que regulam esses gêneros, estará habilitado a se engajar nas práticas letradas que permeiam essa instância. Esse modelo passa a ideia de que a esfera acadêmica é imutável e suas identidades facilmente identificadas, ou seja, uma vez aprendidos os gêneros do discurso específicos das disciplinas, os estudantes se tornariam capazes de reproduzi-los sem problemas.

A abordagem do letramento acadêmico, compartilhada pelos pesquisadores dos Estudos do Letramento, entende os múltiplos letramentos que permeiam a instância universitária como práticas sociais. Assim, o modelo do letramento acadêmico pode ser caracterizado por concentrar-se nos significados que os alunos, professores e universidade atribuem à escrita, partindo de questões epistemológicas que envolvem as relações de poder estabelecidas entre esses sujeitos, no que diz respeito ao uso da língua nessa esfera social pelos próprios participantes.

Assumir essa concepção de letramento implica reconhecer que cada indivíduo ou grupo social possui algum tipo de conhecimento sobre a escrita e seu uso em práticas sociais. Desse modo, os alunos que ingressam na universidade são sujeitos letrados e que, portanto, trazem para essa esfera concepções de leitura e escrita construídas ao longo da sua vida, ainda que essas concepções nem sempre sejam suficientes para que eles se engajem de modo imediato nas práticas letradas do domínio acadêmico. 


\section{A tarefa de produção textual}

Com o propósito de conhecer melhor os alunos que integram a turma (e, nesse caso, participantes da pesquisa) planejou-se uma tarefa de produção textual com tal finalidade. Adota-se a concepção teóricometodológica oferecida por Freire (1993) e por Street (2003): conhecer os participantes e o contexto de ação, pois deles se dará a intervenção.

Acontece que o bom começo para uma boa prática seria a avaliação do contexto em que ela se dará. A avaliação do contexto significa um reconhecimento do que vem nele ocorrendo, como e por quê. Nesse sentido, esse pensar crítico sobre o contexto que implica avaliá-lo, precede a própria programação da intervenção que pretendemos exercer sobre ele, ao lado daqueles e daquelas com quem trabalharemos (Freire, 1993, p.15) .

Assim, a geração de dados desta pesquisa foi viabilizada por uma tarefa de produção textual que orientava o aluno a escrever um texto no qual contasse aos colegas sobre práticas de leitura e escrita vivenciadas por ele durante a sua vida. A finalidade da tarefa consistia em conhecer as experiências de cada aluno em relação à leitura e à escrita, socializar e valorizar conhecimentos prévios dos participantes e direcionar o planejamento do semestre. Os textos circularam pela sala de aula e foram lidos pelos colegas e pela professora, e após foram comentados pelos participantes.

Esse momento foi significativo no sentido de a leitura dos textos ter possibilitado com que os integrantes da turma se conhecessem. Não foram poucos os alunos que, após a leitura de um texto, comentavam sobre questões com as quais se identificavam. Cabe ressaltar especialmente o quanto algumas experiências de leitura e escrita vivenciadas durante o ensino básico foram comentadas pelos alunos. Entre elas, idas à biblioteca, livros cujas leituras eram obrigatórias durante o ensino médio, seminários de leitura organizados pelos professores, etc. Dentre as questões ligadas à escrita, os alunos comentaram muito sobre a dificuldade em escrever alguns textos solicitados pelos seus professores que, muitas vezes, tinham apenas a finalidade de avaliar o estudante.

Embora haja uma ilusão compartilhada de que escrever sobre suas próprias experiências é sempre mais fácil, tem-se a convicção de que essa atividade de escrita não é simples ou espontânea. Os participantes tiveram 
que se lembrar de várias situações vividas (boas ou não), selecioná-las e reavaliá-las tendo em vista a finalidade da escrita e o leitor, no caso, a professora e os demais colegas da turma.

De modo geral, os quarenta e cinco textos produzidos pelos participantes evocaram memórias de leitura e escrita relacionadas à escola de ensino básico. Ao ler os textos, percebi, nas escritas, remissões a reflexões feitas sobre a própria escrita, destacando-se reflexões sobre dois momentos: a escrita antes de entrar na universidade e o ideal de escrita a ser atingido após o ingresso no meio acadêmico. Esses dois momentos trazem à tona, em uma análise à luz do letramento acadêmico, os conflitos existentes entre a escrita que produziam e a que é exigida pelos professores na universidade.

\section{Conflitos: como eu escrevo e como devo passar a escrever}

Para analisar o que os textos evidenciam sobre a escrita antes e após o ingresso na universidade, apresento trechos dos textos destacando aspectos que se repetem nas escritas dos alunos. A identidade dos alunos está suprimida em todos os casos, pois não é relevante para a análise.

Como procedimento de análise, destacam-se os momentos dos textos em que ficam visíveis as oposições expressas pelos autores entre um "antes" e um "depois" de ingressar na universidade. Mais precisamente, busca-se responder às seguintes questões: Quais são os tópicos mais recorrentes que os alunos apresentam em seus textos? Os tópicos selecionados e desenvolvidos pelos alunos em seus textos demonstram algum fato recorrente sobre o que significa entrar na universidade? Os itálicos foram acrescentados por mim, como forma de destaque. Vejamos os seguintes trechos:

1. Antes de ingressar na universidade não tinha uma exigência tão grande nas questões de escrita, e isso foi uma dificuldade que encontrei, ou seja, trabalhar com as regras técnicas (ABNT) na universidade é algo meio complexo, e por eu não ter o conhecimento prévio disso as coisas se tornam mais complicadas."

2. "Na minha vida escolar escrevi muito pouco, quase nada, apenas resumos de outras disciplinas. Sinto que na universidade a minha escrita ainda não está adequada aos textos que preciso escrever." 
3. “Com relação à escrita, acredito que tenha dificuldade de aprofundar por questões profissionais. Como trabalho com TV e propaganda, utilizo a linguagem mais 'falada', coloquial. Aqui na universidade preciso usar uma linguagem mais formal."

4. "As expectativas em relação à universidade são bem positivas, mas sei que vou precisar aprender a escrever outros textos, pesquisar novos conteúdos e compartilhar experiências com outros colegas. Significa que preciso me adaptar às novas exigências."

Nesses quatro trechos, destaco, inicialmente, expressões como antes de ingressar na universidade não tinha uma exigência tão grande nas questões de escrita, na universidade a minha escrita ainda não está adequada aos textos que preciso escrever, aqui na universidade preciso usar uma linguagem mais formal, sei que vou precisar aprender a escrever outros textos, que indicam que os alunos reconhecem que há uma diferença entre os textos que escreviam antes do ingresso na universidade e os que lhes são exigidos pelos professores no meio acadêmico. Essas expressões introduzem práticas que, supostamente, não eram conhecidas pelos estudantes ou que, ao menos, não eram frequentes em contextos anteriores de escrita, como escola.

No conjunto de trechos dos textos abaixo citados, podemos destacar a menção explícita, pelos estudantes, a gêneros que faziam parte de suas práticas de escrita no ensino básico:

5. "Na escola normalmente fazíamos resumos e redações."

6. "Durante o ensino médio uma das propostas da escola era preparar o aluno para a redação do vestibular."

7. "Na escola escrevia músicas e muitos poemas."

8. "No ensino médio a escrita era destinada a variados assuntos, mas a redação se destacava entre os textos que tínhamos que escrever."

9. "O que escrevíamos mais na escola eram redações que a professora pedia a fim de dar nota."

10. "O que mais escrevia no ensino básico eram resenhas, redações, crônicas e charges".

Nesses trechos, talvez a mudança mais significativa tenha sido a consciência de que os textos que devem ser escritos na universidade diferem dos textos que eram escritos no ensino básico.

Se os gêneros que circulam na academia diferem dos acima citados, isso evidencia que o aluno, ao ingressar na universidade, precisa 
engajar-se em uma prática de escrita e leitura até então não familiar para ele.Segundo Street (1994), a escrita acadêmica é um ato social. 0 aluno carrega experiências anteriores de produção de sentidos, ou seja, diferentespráticas que ecoam nas novas práticas que a universidade impõe, em outras palavras, tudo o que o aluno já sabe sobre a escrita é relevante para a escrita que lhe será exigida na universidade.

Trechos de textos de outros estudantes trazem reflexões que se aproximam. Uma recorrência é a referência à escrita com a finalidade de ser avaliado pelo professor, conforme podemos observar no trecho 9 . Vejamos outros exemplos:

11. "A escrita servia para o professor atribuir uma nota."

12. "Minha professora trabalhava com a escrita de textos, mas na hora da prova ela cobrava a gramática."

Para Russel (2009), a avaliação é algo que liga a escrita da educação básica com a escrita no ensino superior. Significa dizer que, para os alunos, a avaliação é conhecida como uma das finalidades comunicativas da produção textual desde o ensino fundamental. Sabemos, no entanto, que essa é apenas uma finalidade e se focarmos nossa atenção na avaliação (notas) isso pode nos afastar das outras finalidades, entre elas, a de fazer com que os alunos escrevam com o propósito de aprender examinando e manipulando ideias, sintetizando, analisando, explorando. Pela recorrência ao aspecto da avaliação, podemos supor que esse é um aspecto muito explicitado nas práticas de escrita escolares, quando a escrita solicitada pelo professor aos seus alunos tem como finalidade avaliá-los. No entanto, parece que os alunos esperam que essa não seja a única finalidade da escrita na universidade, mesmo que saibam que continua sendo uma delas.

Em alguns trechos os estudantes explicitam a sua preocupação em se inserirem nas práticas de escrita da universidade:

13. "Aprender a escrever resumos, resenhas e artigos que tenham a ver com o meu curso."

Esse aspecto explicitado, muito provavelmente, mostra que o estudante tem um objetivo em relação à escrita na universidade, entendido como aprender a escrever determinados textos diferentes dos que escrevia na escola. Trata-se de uma tomada de consciência de que os gêneros textuais que lhe serão exigidos pelos professores na universidade são diferentes daqueles que faziam parte das práticas de leitura e escrita 
antes do ingresso na academia. Cabe ressaltar novamente a importância da experiência como um fator determinante do aprendizado e da apropriação das regras e disposições próprias dos gêneros acadêmicos, sustentando a proposta na teoria de gêneros do discurso formulada por Bakhtin.

Sabemos que a escrita na universidade é algo bastante especializado, muito mais especializado do que no ensino básico. Os alunos necessitam aprender a usar vocabulários especializados. É evidente que a falta de contato com os gêneros acadêmicos faz o aluno perceber a sua dificuldade em escrevê-los. Para Russel (2009, p.241), a escrita "não é uma habilidade generalizável que se aprende de uma vez por todas, mas uma conquista ou feito que pode ser desenvolvido, que requer muita prática”. 0 fato de saber que na universidade o aluno irá deparar-se com gêneros discursivos com os quais ele ainda tem pouco contato causa preocupação, isso pode ser verificado no seguinte trecho:

14. "Assusta-me o fato de ter que escrever um resumo ou uma resenha".

Sobre o trecho acima, é possível afirmar que o aprendizado da língua não é um aprendizado de formas, de uma gramática, mas é constitutiva do processo de socialização, especialmente a língua materna. 0 indivíduo se socializa através da língua; para Bakhtin (1979), através dos gêneros que se constituem por e para as atividades humanas, as interações sociais, em outras palavras, para que o aluno escreva resumos e resenhas precisa necessariamente inserir-se em práticas de leitura e escrita de textos desse gênero.

Nos trechos apresentados acima, confirma-se o conflito que se estabelece entre o que o aluno escrevia antes de entrar no meio acadêmico e a escrita que lhe será exigida pelos professores após o seu ingresso. Além disso, os textos mostram que o discurso dos professores sobre o déficit dos alunos é relevante, ou seja, os próprios alunos reconhecem que sentem dificuldades quando se trata de ler e escrever textos que lhes são exigidos na academia. Conforme Gee (2004), para que os alunos possam assumir-se insiders da comunidade acadêmica precisam entender o funcionamento dos inúmeros discursos que circulam nela, bem como as formas de constituição dos gêneros próprios dessa esfera.

Por outro lado, os textos também mostram que os alunos já escreviam vários textos antes de ingressarem na universidade, significa que eles têm experiências com a escrita. Fato que é incoerente com o discurso de alguns professores que alegam que o aluno não sabe nada. Segundo Gee 
(2004), os alunos encontram dificuldades na escrita acadêmica não por não saberem ler e escrever, mas pelo fato de não terem sido expostos, no ensino fundamental e médio, aos comportamentos linguísticos e sociais específicos do domínio acadêmico.

\section{Considerações finais}

É preciso reconhecer que o aluno é aprendiz da escrita na esfera acadêmica, em outras palavras, para que o aluno passe a compartilhar dos modos de agir, de valorizar, de acreditar do domínio acadêmico e a produzir de forma eficiente os gêneros discursivos dessa esfera, faz-se necessário que ele seja visto como sujeito de linguagem, como de fato o é, e com valores identitários construídos ao longo das suas práticas sociais prévias; esses aspectos são contemplados pelo modelo de letramento acadêmico proposto por Lea e Street (1998).0 fato de os professores projetarem nos textos dos alunos expectativas pouco compatíveis com as suas experiências e conhecimentos sobre esses gêneros pode representar uma relação tensa para o aluno.

Assim, uma das questões que parece ser urgente responder é esta: até que ponto se criam condições para os estudantes serem identificados e se identificarem como membros efetivos de um grupo, o da comunidade discursiva em que têm de ser bem-sucedidos?

Os textos analisados apontam que os alunos também reconhecem que desconhecem os gêneros textuais que integram as práticas de letramento na universidade. Para romper com o discurso do déficit, o planejamento didático do professor também necessita ser repensado/aprimorado, levando em conta as necessidades apresentadas pelos recém-ingressos, possibilitando-lhes o letramento acadêmico. Isso significa conceber o ensino e a aprendizagem como um processo de construção de saberes, não como uma transmissão de conhecimentos. Entretanto, para que esse processo seja exitoso, os objetos de ensino precisam fazer sentido para os alunos.

Adotar uma prática pedagógica que leve em conta o modelo do letramento acadêmico requer aproximar a universidade da vida. Segundo Kleiman (2005), a escrita precisa servir para atingir algum outro fim, que vai além da mera aprendizagem da escrita (a aprendizagem dos aspectos formais apenas), transformando objetivos circulares como "escrever para aprender a escrever" e "ler para aprender a ler" em ler e escrever 
para compreender e aprender aquilo que for relevante para a vida. Ainda, é preciso que a prática pedagógica se ajuste do individual para o social, da língua como código para a língua como interação, do modelo das habilidades para o modelo do letramento acadêmico.

\section{Referências}

BAKHTIN, M. Estética da criação verbal. São Paulo, Martins Fontes, 1997 (Tradução do francês Esthétique de la création verbal), 1979.

BARTON, D. Literacy; an introduction to ecology of written language. 2ed. Oxford: Blackwell Publishing, 2007.

FIAD, Raquel Salek. A escrita na universidade. Revista da ABRALIN, v. Eletrônico, n. Especial, p.357-369. 2 $2^{\mathrm{a}}$ parte, 2011.

FISCHER, A. A construção de letramentos na esfera acadêmica. Tese de Doutorado. Programa de Pós-Graduação em Linguística, Universidade Federal de Santa Catarina. Florianópolis, 2007.

FISCHER, A. Os usos da língua na construção de sujeitos letrados: relações entre a esfera escolar e a acadêmica. Acta Scientiarum. Language and Culture, 32 (2): 215-224, 2010.

FREIRE, Paulo. Professora sim, tia não: cartas a quem ousa ensinar. São Paulo, Olho d'Água,1993.

GEE, J. P. Situated language and learning: A critique of Traditional Schooling. New York: Routledge, 2004.

KLEIMAN, A. (Org.). Os significados do letramento: uma nova perspectiva sobre a prática social da escrita. Campinas: Mercado de Letras, 2005.

HENDERSON, R.; HIRST, E. Reframing academic literacy: re-examining a short course for "disadvantaged" tertiary students. English teaching: practice and critique, 6(2), 2006, p.25-38.

LEA, M. R. \& STREET, B. V. Student writing in higher education: an academic literacies approach. UKStudies in Higher Education, 23(2): 157-172, 1998.

LEA, M. R., \& STREET, B.V. the "academic literacies" model: theory and applications theory into Practice, 45(4), p.368-377, 2006.

LILLIS, T. Whose 'common sense'? Essayist literacy and the institutional practice of mystery. In: JONES, C.; TURNER, J.; STREET, B. (orgs). Students writing in the university: cultural and epistemological issues. Amsterdam. John Benjamins, 1999. p.127-140.

MARINHO, Marildes. A escrita nas práticas de letramento acadêmico. RBLA, Belo Horizonte, v.10, n.2, p.363-386, 2010.

MOTTA-ROTH, Désirée; HENDGES, Graciela Rabuske. Produção textual na universidade. São Paulo: Parábola Editorial, 2010. 
RUSSEL, D. R., LEA, M.; PARKER, J.; STREET, B.; DONAHUE, T. Exploring notions of genre in "academic literacies" and "writing across the curriculum": Approaches Across Coutries and Contexts. In: Bazerman, C.; Bonini, A. \& Figueiredo, D. (Eds.). Genre in a Chaging World. Colorado: The WAC Clearinghouse, 2009. Ch. 20, p.395423. Disponível em: http://wac.colostate.edu/books/genre/

STREET, B. Literacy in theory and practice. Cambridge: CUP, 1994.

STREET, B. What's "new" in new literacy studies? Critical approaches to literacy in theory and practice 2003. Current Issues in Comparative Education, 5 (2), 2003. 